\title{
The growth traits of microalgae for biofuel and its effect on nitrogen and
}

\section{phosphorus removal in waste water}

\author{
Jiang Yu, ${ }^{1,2, a^{*}}$, Ziyi $S u^{1,2 b}$, Ping Wang ${ }^{1,2 c,}$ Yuting Zhou ${ }^{1,2 d}$ \\ 1 College of Architecture and Environment, Sichuan University, Chengdu, China 610065 \\ 2 Institutes of New Energy and Low Carbon Technology, Sichuan University, Chengdu, China 610065 \\ a yujiangggz@163.com, b398410869@qq.com,,1158427848@qq.com,,937621192@qq.com
}

Keywords: Microalgae; Biofuel; Wastewater; Removal of nitrogen and phosphorous

Abstract: Four species of microalgae were chosen in this research, including two American species, Chlammydomonas reinhardtii (CHRE for short) and Scenedesmus obliquus(SCOB), as well as two domestic species Chlamydomonas sajiaoLewin (CHSA) and Scenedesmus obliquus (SCOBC) in order to analyze the nitrogen and phosphorus removal effects and growth traits of different micro-algae species under different culture condition. The results showed the removal rates of TN (total nitrogen) of CHRE, CHSA, SCOB and SCOBC were 48.42\%, 35.94\%, 42.51\%, 36.16\%, respectively. For TP (total phosphorus), they are 97.83\%, 96.82\%, 96.82\% and $95.86 \%$, respectively. And for NH3-N (Ammonia nitrogen), the removal rates are 51.88\%, 33.61\%, 49.60\% and 35.89\%, respectively. Among them, C.reinhardtii has performed a significant advantage in the nitrogen and phosphorus removal. Furthermore, it also filters the potential suitable species for local area is C.reinhardtii.

\section{Introduction}

The characteristics of China's resource structure are rich in coal, poor of oil and lack for gas. One effective way to cope with the scarce supply of diesel market is cultivating microalgae for biofuel, which has colossal potential for newly-developing alternative energy ${ }^{[1-4]}$. Meanwhile, with a sharp deterioration happened in a large scale of domestic water area, the excessive of nitrogen and phosphorus in water become to an urgent problem to be solved. Introducing the waste water into microalgae cultivation system couldn't only achieve the nitrogen and phosphorus removal but also producing enormous alga biomass, which could be used to produce biofuel ${ }^{[5-7]}$. Therefore, the chief purpose of this study is to select the potential species fit in local waste water and build the optimized cultivation system for microalgae.

\section{Materials and Methods}

\section{Source and pre-culture of species}

The species used in this study are Chlorella and Scenedesmus. Among them, CHRE and SCOB are from algal biotechnology center of UC San Diego, while CHSA and SCOBC are from Bioscience College of Sichuan University.

Four species stock cultures were maintained in $250 \mathrm{~mL}$ Erlenmeyer flasks containing $100 \mathrm{~mL}$ WC medium closed with a cellulose stopper. The flasks were placed at $20{ }^{\circ} \mathrm{C}$ in $50 \pm 5 \mu \mathrm{mol}$ photons $\mathrm{m}^{-2}$ $\mathrm{s}^{-1}$ provided in a 12:12 h light-dark cycle. Prior to the experiment, the microalgae were acclimatized to the experimental conditions. 


\section{Experimental design}

The experiment was performed in $150 \mathrm{ml}$ Erlenmeyer flasks containing $50 \mathrm{ml}$ using WC medium and wastewater from the STP (sewage treatment plant) in Airport Development Zone (Chengdu) under the culture condition of temperature of $20{ }^{\circ} \mathrm{C}$, light supply of $50 \pm 5 \mu \mathrm{mol}$ photons m $\mathrm{m}^{-2}$, taking out $5 \mathrm{ml}$ culture solution every two days to determine microalgae cells, observe the growth condition of cells, measure the $\mathrm{TN}, \mathrm{TP}, \mathrm{NH}_{3}-\mathrm{N}$ contents and the removal rates of nitrogen and phosphorus at the same time.

Statistical Analysis

Statistical analyses were done with the software SPSS, mainly using one-way and two-way analysis of variances (ANOVA), the level of significance at $\mathrm{P}<0.05$ or 0.001 .

\section{Results and Discussion}

The growth conditions

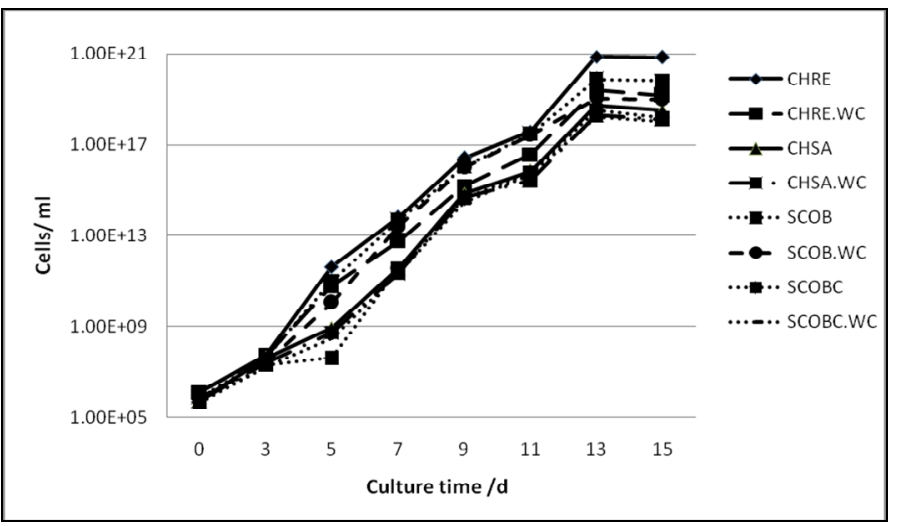

Fig. 1 Concentration variation of micro-algae cells

From Fig. 1, the similar trend was observed in four species under different culture conditions, that's, the cell concentration increased with the culture time, and all reached to be stable at the culture time arriving to $13 \mathrm{~d}$ or so. Also it's found that CHRE, SCOB, CHSA and SCOBC all grew in wastewater better and faster than grew in WC medium which was set control group. Specially, CHRE grew best and fastest among all species and in two culture condition (ANOVA, $\mathrm{P}<0.05$ ).

The removal effects of $\mathrm{N}, \mathrm{P}$, and $\mathrm{NH}_{3}-\mathrm{N}$ in wastewater

As shown in Fig. 2 and Fig.3, in the first three days, except for the TN in SCOBC with a general stable state, the other three species had a decrease in TN. The TN removal rates of CHRE, CHSA, SCOB, and SCOBC were 48.42\%, 35.94\%, 42.51\%, 36.16\%, respectively. As shown in Fig.4 and Fig.5, the TP removal rates of CHRE, CHSA, SCOB, and SCOBC were 97.83\%, 96.82\%, 96.82\%, $95.86 \%$, respectively. From the tendency of nitrogen and phosphorus in the water, we can see the concentration would go through a steep reduction at first, then decrease slowly, and pick up until reach to a table value in the end. When it came to the removal rate, different species showed a diverse capacity in the removal of N/P. What is more, four species all present a preferable ability in the removal of phosphorus than nitrogen; it might be concerned with the eco-physiological characteristics of these species. However, the reason remains to be investigated further. From Fig.6 and Fig.7, CHRE and SCOB had a generally identical final concentration of $\mathrm{NH}_{3}-\mathrm{N}$, so did CHSA and SCOBC. However, the former two were apparently lower than the later $(\mathrm{P}<0.05)$. The removal rate of $\mathrm{NH}_{3}-\mathrm{N}$ in $\mathrm{CHRE}$, CHSA, SCOB and SCOBC towards the same wastewater were 51.88\%, $33.61 \%, 49.60 \%, 35.89 \%$, respectively, with a descending order as follows: CHRE, SCOB, SCOBC, CHSA. 

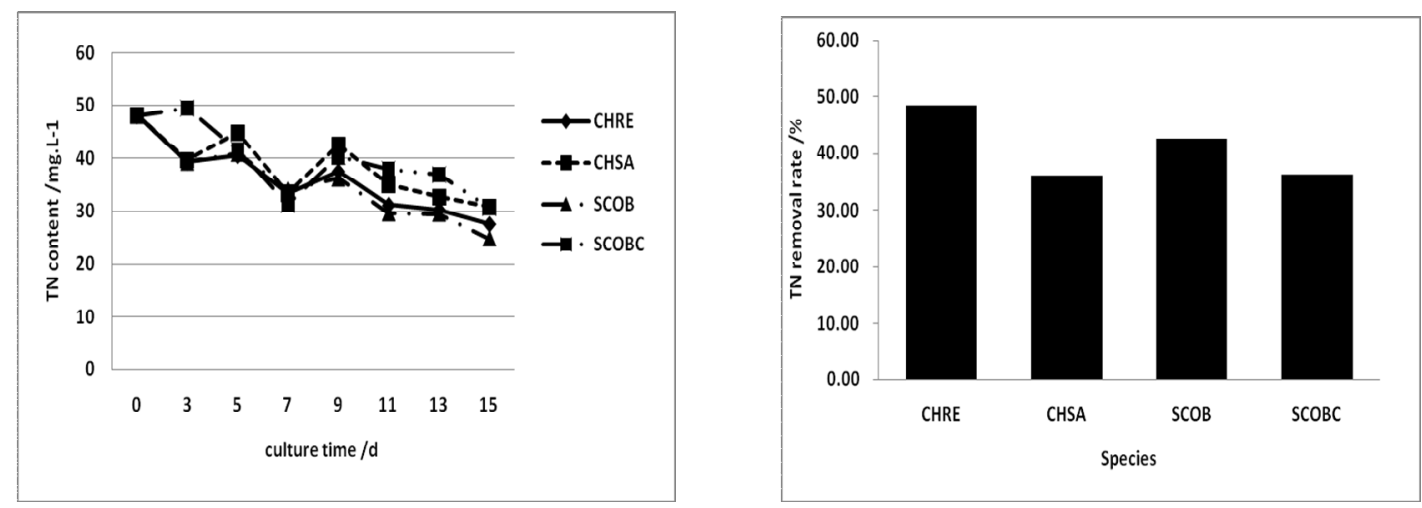

Fig.2 Changes in TN contents of different species

Fig. 3 The removal rate of TN
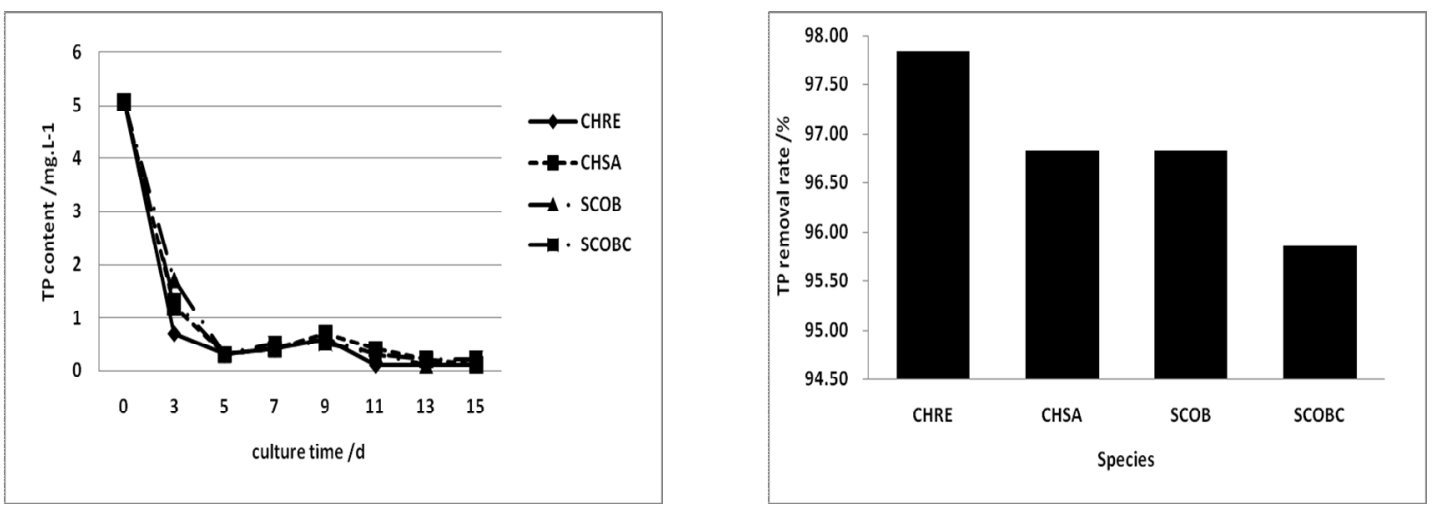

Fig.4 Changes in TP contents of different species

Fig.5 The removal rate of TP
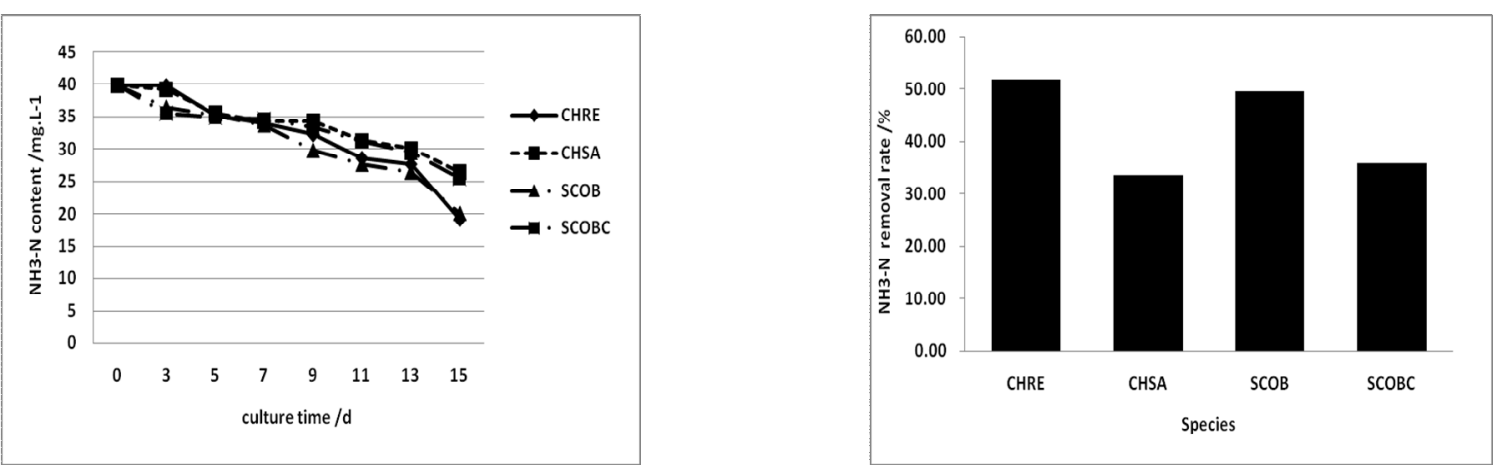

Fig.6 Changes in $\mathrm{NH}_{3}-\mathrm{N}$ contents of different species

Fig. 7 The removal rate of $\mathrm{NH}_{3}-\mathrm{N}$

\section{Conclusion}

The study with a view to determine the growth properties and removal effect on N/P in the water, has discovered cultivating in the medium from waste water of a STP , the removal rates of TN among CHRE,CHSA, SCOB and SCOBC were 48.42\%, 35.94\%, $42.51 \%$ and $36.16 \%$, respectively. For TP, they were $97.83 \%, 96.82 \%, 96.82 \%$ and $95.86 \%$. For $\mathrm{NH}_{3}-\mathrm{N}$, the removal rates were $51.88 \%, 33.61 \%, 49.60 \%$ and $35.89 \%$, respectively. For the wastewater from the STP, Chlorella and Scenedesmus are about the same overall. But the foreign species has a prominent superiority in the removal process.

\section{Acknowledgements}

The study is supported by Chengdu Technology Bureau, Science Foundation of Sichuan Province (2014JY0224), and Science Foundation of China (31100374). 


\section{References}

[1] P. T. Vasudevan, M. Briggs, Biodiesel production-current state of the art and challenges. J. Indus. Micro. Bio. 35 (2008) 421-430.

[2] M. Fatih, Biofuels from algae for sustainable development. Appl. Energy. 88 (2011) 3473-3480.

[3] Y.Chisti, Biodiesel from microalgae. Bio. Advance. 25 (2007) 294- 306.

[4] L. Miao, Q. Y. Wu, Biodiesel production from heterotrophic microalgal oil. Bio. Tech. 6 (2006) 841-846.

[5] H. Hu, Analysis of key techniques and production potential of biodiesel production based on microalgae with waste-water as resources. Ecol. Environ. Sci. 3 (2010) 739-744.

[6] S. Aslan, K. Kapdani, Batch kinetics of nitrogen and phosphorus removal from synthetic wastewater by algae. Ecol. Engine. 28 (2006) 64-70.

[7] V. Rudolph, Y. He, Research and development trends in biodiesel. Develop. Chem. Engine. Mine. Proc. 12 (2004) 461-474. 